\title{
Monsoonal Influences on Offshore Rapid Intensification of Landfalling Typhoons in a Sheared Environment over the South China Sea
}

\author{
WENYU QIU \\ Key Laboratory of Meteorological Disaster, Ministry of Education, Nanjing University of Information Science and \\ Technology, Nanjing, and State Key Laboratory of Severe Weather, Chinese Academy of Meteorological Sciences, \\ Beijing, China \\ LIGUANG WU \\ Department of Atmospheric and Oceanic Sciences, and Institute of Atmospheric Sciences, Fudan University, Shanghai, China \\ FUMIN REN \\ State Key Laboratory of Severe Weather, Chinese Academy of Meteorological Sciences, Beijing, China
}

(Manuscript received 2 July 2019, in final form 22 January 2020)

\begin{abstract}
Tropical cyclones (TCs) formed in the western North Pacific and South China Sea can undergo rapid intensification (RI) shortly before making landfall in China. Forecasting such offshore RI is a great challenge in operations. In this study the offshore RI events in a sheared environment are examined for TCs that made landfall in China during 1979-2017. It is found that there were only three offshore RI events in a sheared environment, all of which occurred to the south of Hainan Island within the monsoon trough in early to midJuly, coinciding with the termination of the mei-yu season. The specific geographic location and timing of the occurrence of the offshore RI in the sheared environment is associated with the adjustment of the East Asia summer monsoon system when the mei-yu season terminates in the Yangtze River valley. In addition to the adjustment favorable for TC intensification by enhancing the TC-trough interaction in the upper troposphere, this study suggests that two environmental factors also contribute to the offshore RI over the South China Sea in a sheared environment. One is the intrusion of dry air associated with the western North Pacific subtropical high (WNPSH) and the other is the penetration of the water vapor flux associated with the monsoon surge. The adjustment of the East Asia summer monsoon system allows the water vapor flux of the monsoon surge to penetrate the TC circulation and prevents the dry air of the WNPSH from intruding into the TC circulation.
\end{abstract}

\section{Introduction}

Tropical cyclones (TCs) often experience rapid intensification (RI) during their lifetime, especially for intense TCs, and forecasting the RI is currently a great challenge in operations (Titley and Elsberry 2000; Kaplan and DeMaria 2003; Wang and Zhou 2008; Shu et al. 2012). Chinese forecasters have long noticed that TCs formed in the western North Pacific and South China Sea can undergo RI shortly before making landfall (e.g., Liu and Rong 1995), leading to a very short time period for authorities to execute evacuation. While

\footnotetext{
Corresponding author: Prof. Liguang Wu, liguangwu@fudan. edu.cn
}

studies suggested that the favorable large-scale environmental conditions are important for RI (Kaplan and DeMaria 2003; Hanley et al. 2001; Kaplan et al. 2010; Shieh et al. 2013; Wang et al. 2015; Chen et al. 2015), recent studies have demonstrated that RI can occur in an environment with vertical wind shear (VWS) larger than $10 \mathrm{~m} \mathrm{~s}^{-1}$ (Molinari et al. 2006; Molinari and Vollaro 2010). It is argued that convective bursts inside the radius of maximum wind play an important role in the RI in a sheared environment (Reasor et al. 2009; Rogers et al. 2016; Zawislak et al. 2016; Chen et al. 2018; Leighton et al. 2018). This finding further complicates the forecast of offshore RI, which is particularly important for disaster mitigation and prevention of landfalling TCs in China. 
It has been found that RI is more likely to occur in the large-scale environment with lower VWS, warmer sea surface temperature (SST), higher oceanic heat content, and higher relative humidity in the low- to midtroposphere (Kaplan and DeMaria 2003; Kaplan et al. 2010; Chen et al. 2015). Other favorable environmental factors include external forcing from upper-level systems (Hanley et al. 2001; Shieh et al. 2013; Chen et al. 2015). In the western North Pacific and South China Sea, the large-scale conditions are closely associated with the summer monsoon system, including the monsoon trough (MT) in the lower troposphere, the western North Pacific subtropical high (WNPSH) and the South Asia high (SAH) in the upper troposphere. Wang and Zhou (2008) examined the climatic variability of the RI on seasonal, intraseasonal, interannual, and interdecadal time scales, suggesting that these oscillations of the monsoon circulation can play an important role in the RI over the western North Pacific and the South China Sea. However, it is not well understood how the monsoon system affects the offshore RI of TCs in a sheared environment.

The objective of this study is to examine the monsoonal influences on the offshore RI of TCs that made landfall in China in a sheared environment during the period 1979-2017. The data and methodology are described in section 2, and the identification of the offshore RI events in a sheared environment is presented in section 3. The large-scale environmental circulation associated with the offshore RI in a sheared environment is discussed in section 4 , followed by discussion and conclusions in sections 5 and 6 .

\section{Data and methodology}

The TC data in the western North Pacific and South China Sea are obtained from the best track dataset of the Shanghai Typhoon Institute (STI) of the China Meteorological Administration (CMA). Similar to other best track datasets, the STI dataset includes the maximum wind speed, minimum central sea level pressure, and the latitudes and longitudes of the TC center at 6-h intervals (Ying et al. 2014). In addition, the STI dataset also includes the time, latitude and longitude, the maximum wind speed, and minimum central sea level pressure when the TC made landfall in China. When a TC moves to the offshore of China, the STI dataset utilizes radar data and observations from islands and buoys, usually in a shorter time interval. These additional data should be beneficial to the estimation of TC intensity and center position when the TC was off the shore of China.

The ERA5 reanalysis from the European Centre for Medium-Range Weather Forecasts (ECMWF) is used for examining the large-scale conditions and circulations. Our analysis focuses on the period 1979-2017 since the TC intensity records were more reliable since 1979 (Wu and Zhao 2012). As shown by Zong and Wu (2015), the large-scale circulation derived from the reanalysis data can be contaminated by the TC circulation. Hsu et al. (2008) also demonstrated that extreme events such as TCs can contribute significantly to the timeaveraged field. For this reason, the large-scale circulation in this study is derived based on a two-step procedure. The TC circulation is first removed with the procedure proposed by Kurihara et al. $(1993,1995)$ and then a 10-day low-pass Lanczos filter is applied to the resulting environmental variables. Since the TC circulation can interact with the large-scale circulation, we also use the difference between the unfiltered and filtered fields to examine the possible interaction of the TC circulation with the environment. Note that the TC structure and the associated interactions contain considerable uncertainty due to the inaccurate representation of the TC circulation in the relatively coarse-resolution reanalysis. Following previous studies (Kaplan and DeMaria 2003; Shu et al. 2014), the VWS is calculated within a radius of $220-880 \mathrm{~km}$ from the TC center. The sea surface temperature (SST) data are from National Oceanic and Atmospheric Administration Extended Reconstructed SST version 4 (ERSST v4) dataset (Huang et al. 2015).

Following Molinari et al. (1995), the relative eddy flux convergence (REFC) is defined as:

$$
\mathrm{REFC}=-\frac{1}{r^{2}} \frac{\partial}{\partial r} r^{2} \overline{u_{L}^{\prime} v_{L}^{\prime}},
$$

where $u$ and $v$ are the radial and azimuthal velocity components, respectively; $r$ is the distance from the storm center; and primes indicate the deviation from the azimuthal mean (which is represented with an overbar). The subscript $L$ refers to storm-relative flow since REFC is calculated in a storm-following coordinate system. REFC is an indicator of TC-trough interaction in spite of coarse reanalysis data (Chen et al. 2015). REFC in this study is calculated at $200 \mathrm{hPa}$ over 220 $880-\mathrm{km}$ radii from the TC center.

An RI event is defined when the maximum sustained surface wind speed of a TC increases by at least $15.4 \mathrm{~m} \mathrm{~s}^{-1}$ over a 24-h period (Kaplan and DeMaria 2003; Qin et al. 2016). The RI onset time is the beginning time of the RI over a 24-h period. For a comparison, we also define the weakening event when the maximum sustained wind speed of a TC decreases by at least $5 \mathrm{~m} \mathrm{~s}^{-1}$ over a 24-h period. The offshore RI and weakening events are defined for those TCs that made landfall in China mainland and Hainan Island within $36 \mathrm{~h}$ and were located within a radius of $850 \mathrm{~km}$ from the landfalling location. For the RI 
and weakening events, the TCs with tropical storm intensity at the onset time are examined.

\section{Offshore RI events in a sheared environment}

Based on the definition in the last section, 24 offshore RI events are detected during the period 1979-2017. Figure 1a shows the track segment (red) of TCs during the offshore RI episode. There are 21 offshore RI events in the South China Sea and the other three occurred in the East China Sea. Some of the RI events lasted more than $24 \mathrm{~h}$ and even until shortly before a TC made landfall. More than half of the TCs that experienced the offshore RI made landfall in Hainan Island and Leizhou Peninsula in Guangdong province. In agreement with Liu and Rong (1995), the South China Sea is the most active region for the occurrence of the offshore RI events. Further examination indicates that there are 13 offshore RI events that occurred in July-September.

To compare the large-scale conditions for the 13 offshore RI events in July-September, we also identified 16 weakening events that occurred in July-September over the South China Sea during the period 1979-2017. We compared the TC intensity, VWS, SST, and 600-hPa relative humidity $(\mathrm{RH})$ at the onset time; it is found that the significant differences are only found in the VWS and TC intensity between the RI and weakening events. The average onset intensity is 26.4 and $38.3 \mathrm{~m} \mathrm{~s}^{-1}$ for the RI and weakening events, respectively, indicating that the weakening event occurs mostly for TCs with typhoon strength. The average VWS is 7.9 and $11.1 \mathrm{~m} \mathrm{~s}^{-1}$ for the RI and weakening events, respectively. In agreement with previous studies, VWS generally is an inhibiting environmental factor for the offshore RI.

However, some TCs can still experience offshore RI when the VWS between 200 and $850 \mathrm{hPa}$ is larger than $10 \mathrm{~m} \mathrm{~s}^{-1}$. We also examined RI events in the western North Pacific basin west of $150^{\circ} \mathrm{E}$ in JulySeptember during the period 1979-2017. A total of 151 RI events were identified, with 129 and 22 RI events over the western North Pacific and the South China Sea, respectively. Calculation of the VWS using the low-pass-filtered data indicates that four (eight) events over the South China Sea (the western North Pacific) experienced the VWS of greater than $10 \mathrm{~m} \mathrm{~s}^{-1}$ during the whole RI period. That is, $18.2 \%(6.2 \%) \mathrm{RI}$ events occurred in a sheared environment with VWS greater than $10 \mathrm{~m} \mathrm{~s}^{-1}$ during the whole RI period over the South China Sea (the western North Pacific), suggesting that the South China Sea is a relatively active region for the occurrence of the RI in a sheared environment.
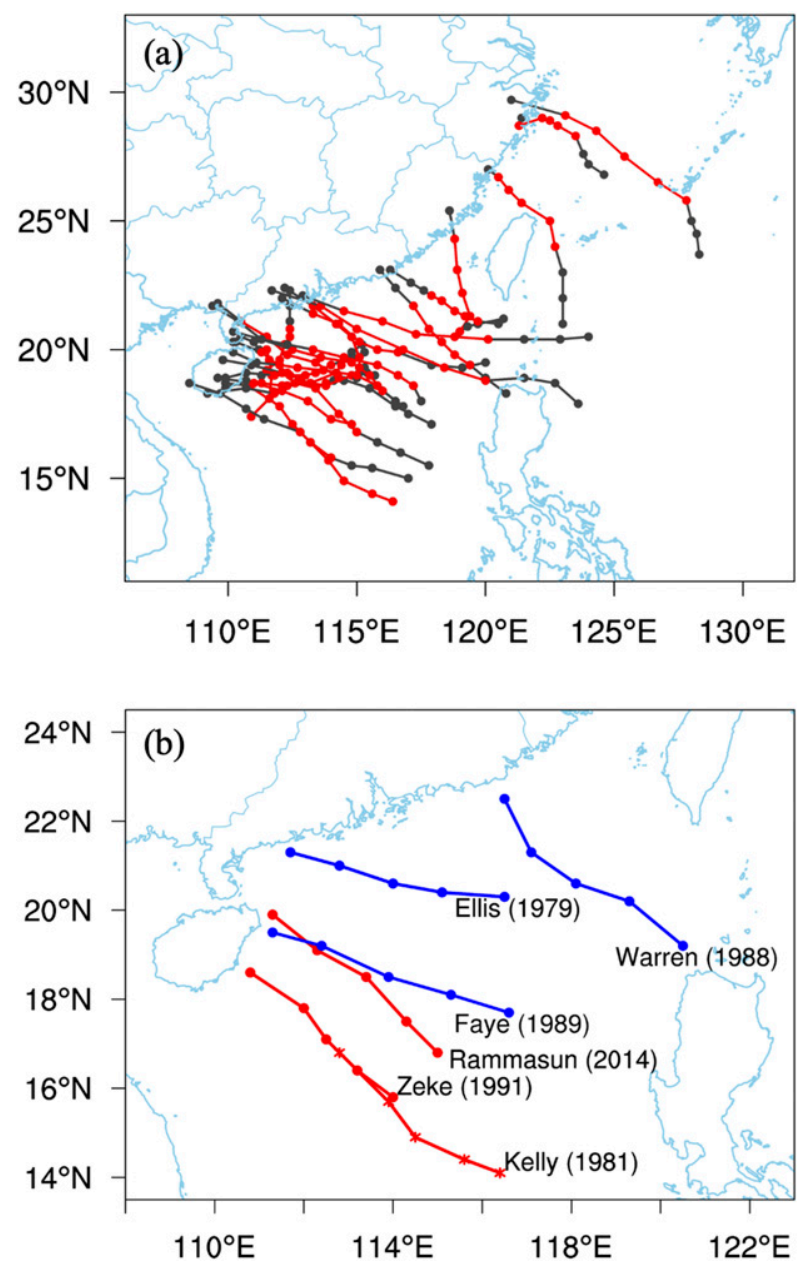

FIG. 1. (a) Track segments of TCs that experienced offshore RI in during 1979-2017, with red lines indicating the RI episode. (b) The RI (red) and weakening (blue) track segments that occurred in a sheared environment in early to mid-July.

Among of the 13 offshore RI events over the South China Sea in July-September, three RI events took place when VWS exceeded $10 \mathrm{~m} \mathrm{~s}^{-1}$ and then made landfall in China within $36 \mathrm{~h}$ (Fig. 1b). The three TCs are Typhoons Kelly (1981), Zeke (1991), and Rammasun (2014). It is interesting that the three RI events all occurred in early to mid-July and moved across the Philippines and experienced offshore RI to the southeast of Hainan Island in the South China Sea. As suggested by Holliday and Thompson (1979), RI events occur over warm oceans with SSTs not lower than $28^{\circ} \mathrm{C}$. As shown in Table 1, the SST associated with the three offshore RI events are all above $28^{\circ} \mathrm{C}$. Figure 2 a shows the 24-h intensity change of the three TCs relative to the RI onset $(t=0 \mathrm{~h})$ and the corresponding VWS is shown in Figs. 2b and 2c. The intensity of Kelly, Zeke, and Rammasun was 25,25 , and $45 \mathrm{~m} \mathrm{~s}^{-1}$, respectively. 
TABLE 1. List of the SST and the environmental parameters for the three RI cases (Kelly, Zeke, Rammasun) and three weakening cases (Ellis, Warren, Faye) at the onset.

\begin{tabular}{|c|c|c|c|c|c|c|}
\hline \multirow{2}{*}{$\begin{array}{c}\text { Parameter } \\
\text { TC name }\end{array}$} & \multicolumn{3}{|c|}{ RI } & \multicolumn{3}{|c|}{ Weakening } \\
\hline & Kelly (1981) & Zeke (1991) & Rammasun (2014) & Ellis (1979) & Warren (1988) & Faye (1989) \\
\hline $\operatorname{SST}\left({ }^{\circ} \mathrm{C}\right)$ & 28.7 & 28.5 & 30.1 & 29.2 & 29.8 & 29.3 \\
\hline Filtered VWS $\left(\mathrm{m} \mathrm{s}^{-1}\right)$ & 15.1 & 13.1 & 13 & 14.3 & 11.7 & 14.1 \\
\hline Unfiltered VWS ( $\left.\mathrm{m} \mathrm{s}^{-1}\right)$ & 14.6 & 11.3 & 9.8 & 16.4 & 12.0 & 15.9 \\
\hline $\operatorname{REFC}\left(\mathrm{m} \mathrm{s}^{-1} \mathrm{day}^{-1}\right)$ & 11.3 & 9.3 & 1.4 & -0.1 & -0.5 & -2.7 \\
\hline 600-hPa filtered relative humidity (\%) & 73.5 & 73.2 & 72.9 & 66.8 & 62.1 & 62.4 \\
\hline Westernmost extension of WNPSH $\left({ }^{\circ} \mathrm{E}\right)$ & 119 & 114 & 112 & 110 & 112 & 108 \\
\hline Latitude of WNPSH ridge at $120^{\circ} \mathrm{E}\left({ }^{\circ} \mathrm{N}\right)$ & 26 & 25 & 26 & 26 & 28 & 25.5 \\
\hline
\end{tabular}

Note that the intensity change of Kelly and Zeke was identical during the period of the RI.

The VWS in the low-pass-filtered data at the RI onset was 15.1, 13.1, and $13.0 \mathrm{~m} \mathrm{~s}^{-1}$ for Kelly, Zeke, and Rammasun (Table 1). During the RI episode, the VWS for the three RI cases was larger than $10.0 \mathrm{~m} \mathrm{~s}^{-1}$ (Fig. 2c). We also calculated the VWS using the unfiltered data. The VWS in the unfiltered data is $14.6,11.3$, and $9.8 \mathrm{~m} \mathrm{~s}^{-1}$ at the RI onset for Kelly, Zeke, and Rammasun (Table 1), respectively. During the RI episode, the VWS in the unfiltered data was at least $8.0 \mathrm{~m} \mathrm{~s}^{-1}$ (Fig. 2b). The VWS (larger than $10 \mathrm{~m} \mathrm{~s}^{-1}$ ) in the low-pass-filtered data suggests that the three TCs experienced a relatively hostile large-scale environment at the beginning of the RI. Previous studies suggest that VWS larger than $5 \mathrm{~m} \mathrm{~s}^{-1}$ is generally considered hostile to TC intensification (Kaplan and DeMaria 2003; Kaplan et al. 2010).

\section{Large-scale circulation associated with the offshore RI event}

The above analysis revealed two interesting features for the offshore RI in the sheared environment. One is the specific geographic location of the occurrence of the offshore RI. All the three identified RI events took place to the southeast of Hainan Island and the corresponding TCs took a northwestward track. The other is that the three RI events in the sheared environment all occurred in early to mid-July. It is suggested that the large-scale circulation plays a role in the timing and geographic location of the occurrence of the three RI events in the sheared environment.

We first examined the climatologic mean 200-, 500-, and 850-hPa wind fields in July. In the upper troposphere $(200 \mathrm{hPa})$ (Fig. 3a), the South China Sea is controlled by the easterly of the south flank of the SAH. The ridge of SAH is located along $\sim 30^{\circ} \mathrm{N}$ and extends over the western North Pacific. In the middle troposphere $(500 \mathrm{hPa})$ (Fig. 3b), the WNPSH extends westward to $105^{\circ} \mathrm{E}$ over China mainland. The ridge of the WNPSH is about $27^{\circ} \mathrm{N}$ at $120^{\circ} \mathrm{E}$. The southwesterly monsoon flow from the Bay of Bengal meets the southeasterly flow of the WNPSH at $850 \mathrm{hPa}$, constituting the MT (Fig. 3c). The RI events occurred in the climatologic monsoon trough, which extends southwestward beyond $135^{\circ} \mathrm{E}$ and the VWS in the South China Sea resulted mainly from the strong easterly winds associated with the SAH and the southwesterly monsoon flow.

For a comparison, we selected three weakening events that also occurred in the South China Sea in early to mid-July. They were Typhoons Ellis (1979), Warren (1988), and Faye (1989). As shown in Fig. 1b, the three weakening cases in the South China Sea were generally located to the north of the RI cases. The comparisons of the VWS derived from the low-pass and unfiltered data are given in Table 1 . The three weakening TCs also experienced strong VWS. As shown in Table 1, the VWS between 200 and $850 \mathrm{hPa}$ calculated from the unfiltered data is $16.4,12.0$, and $15.9 \mathrm{~m} \mathrm{~s}^{-1}$ at the beginning of weakening, while the VWS derived from the lowpass-filtered data is $14.3,11.7$, and $14.1 \mathrm{~m} \mathrm{~s}^{-1}$ at the onset for Ellis, Warren, and Faye, respectively. The VWS shows no significant change during the weakening period (Figs. 2b,c). The VWS is generally comparable to those of the three RI cases in magnitude. In addition, the three weakening cases also occurred in the climatologic monsoon trough (Fig. 3c). Compared to the RI cases, the TC intensity at the beginning of weakening was 30, 40, and $30 \mathrm{~m} \mathrm{~s}^{-1}$ for Ellis, Warren, and Faye, respectively, indicating no significant difference in the onset intensity between the RI and weakening cases. Moreover, the SST with the three weakening events was $29.2^{\circ}$, $29.8^{\circ}$, and $29.3^{\circ} \mathrm{C}$ for Ellis, Warren and Faye, respectively (Table 1), and there was no significant difference in SST between the RI and weakening events. Thus, given the similar geographic location and timing of the occurrence, the comparison of the three offshore RI cases with the three weakening cases can help understand the mechanisms responsible for the offshore RI in a sheared environment.

We further examined the differences in the large-scale circulation between the three offshore RI and weakening 

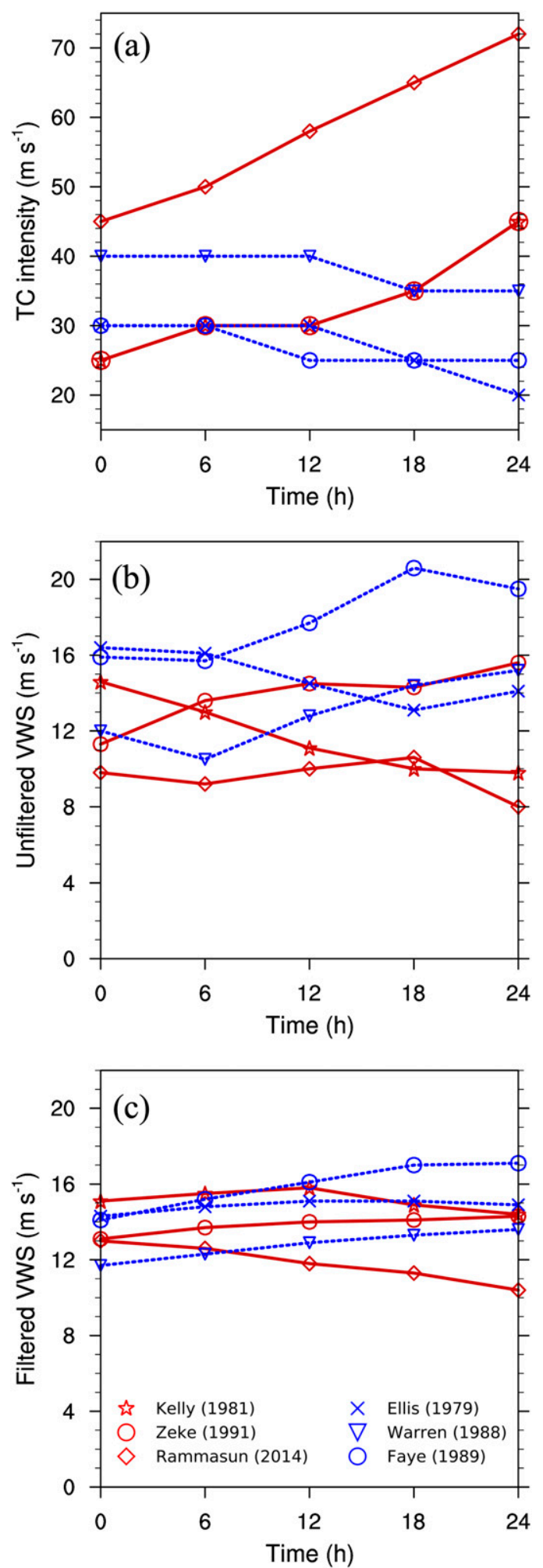

FIG. 2. (a) The 24-h intensity changes and (b),(c) 24-h changes of VWS relative to the onset $(t=0 \mathrm{~h})$ for the RI cases of Kelly (1981), Zeke (1991), and Rammasun (2014) and the weakening cases of Ellis (1979), Warren (1988), and Faye (1989).
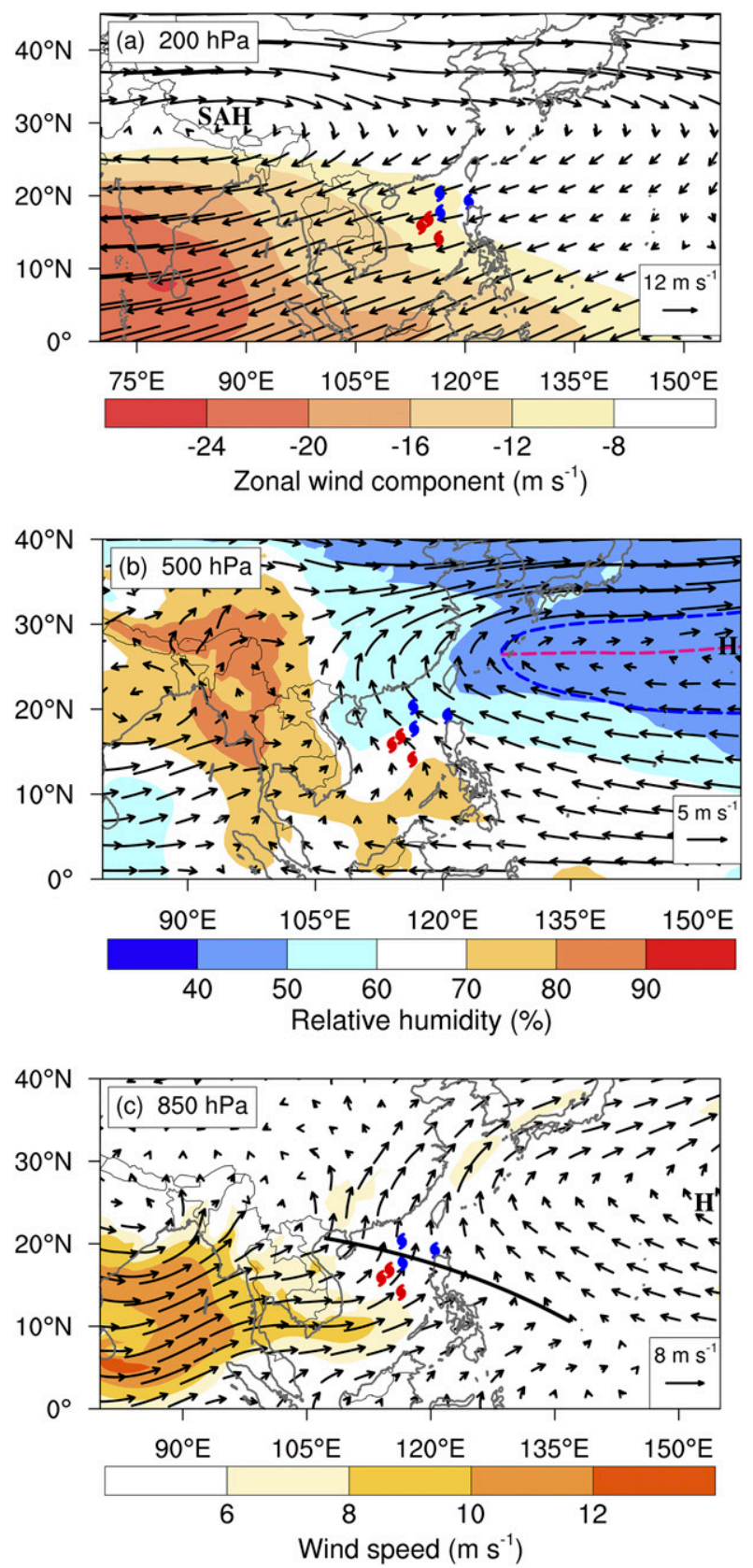

FIG. 3. Climatologic 200-, 500-, and 850-hPa filtered wind fields (vectors) with the shading indicating the (a) filtered zonal wind component, (b) 500-hPa relative humidity, and (c) wind speed, which are averaged in July over the period 1979-2017. The red (blue) typhoon symbol indicates the position of the TC center at the onset of the RI (weakening) cases. The ridges of the WNPSH and monsoon trough are also indicated.

cases. Figure 4 compares the 200-hPa wind field for the three RI cases and three weakening cases. For the RI cases, the SAH shrank westward in the case of Kelly, while it split into two centers over China and over the western North Pacific in the cases of Zeke and Rammasun. 
RI
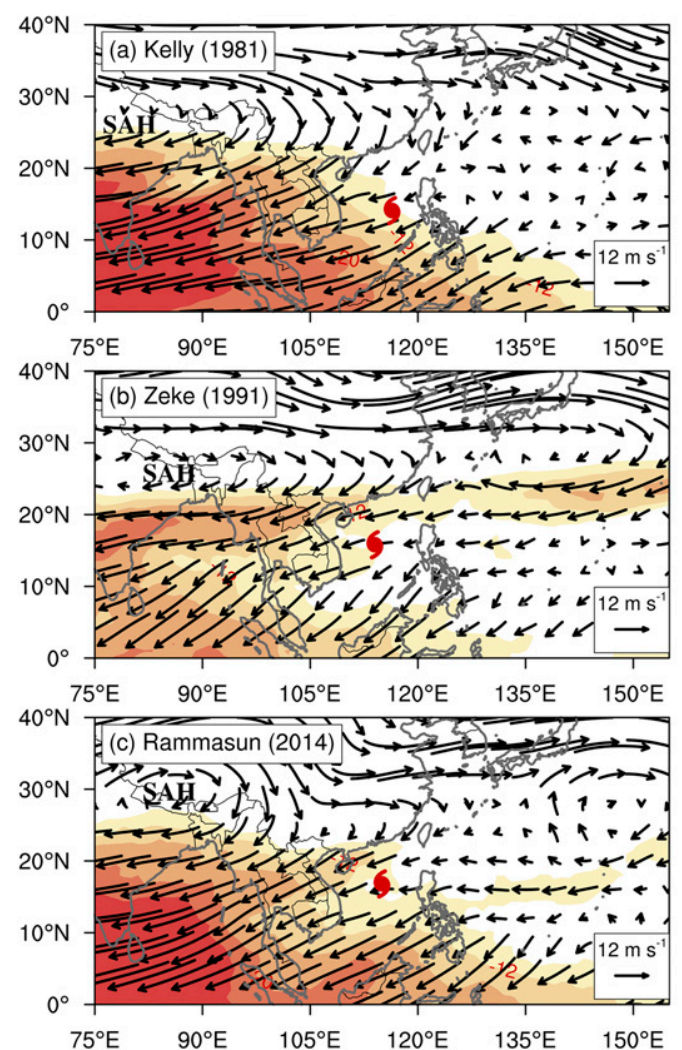

Weakening
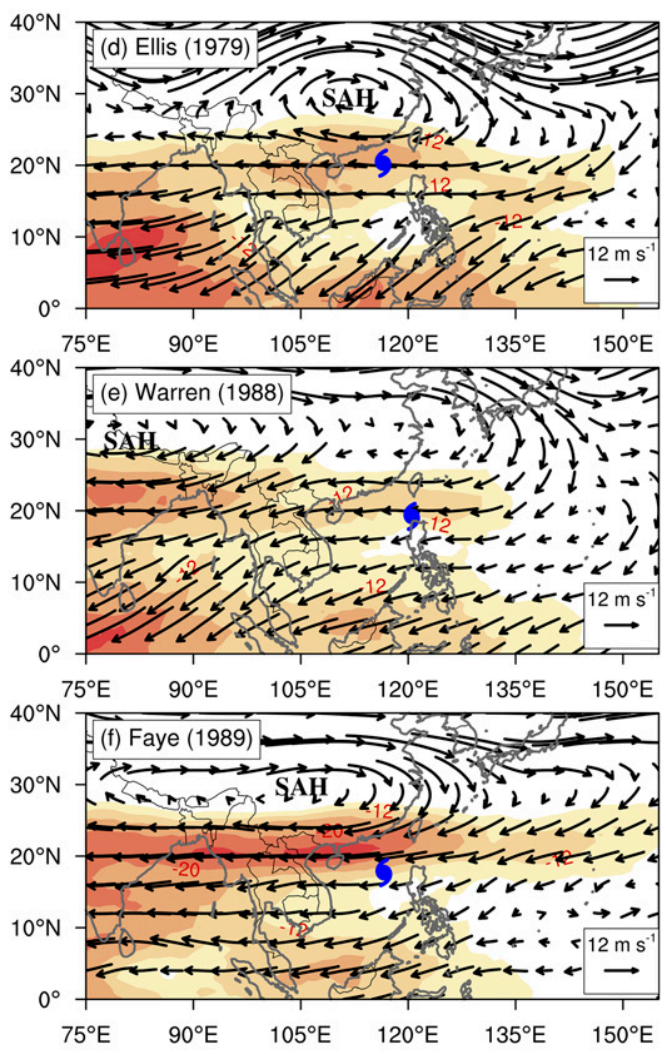

$-24$

$\begin{array}{cc}-20 & -16 \\ \mathrm{u} \text { component of wind }\left(\mathrm{m} \mathrm{s}^{-1}\right)\end{array}$

FIG. 4. The 200-hPa filtered wind field (vectors) and zonal wind component (shaded) at the onset for the RI cases of Typhoons Kelly (1981), Zeke (1991), and Rammasun (2014) and the weakening cases of Typhoons Ellis (1979), Warren (1988), and Faye (1989). The red (blue) typhoon symbol indicates the position of the TC center at the onset of the RI (weakening) cases.

The ridge of the SAH was between $25^{\circ}$ and $30^{\circ} \mathrm{N}$. For the weakening cases, on the other hand, the SAH extended eastward in the case of Warren, while there was an anticyclone center to the north of Ellis and Faye. We can see that the three RI cases were located to the southeast flank of the SAH with the SAH centered west of $90^{\circ} \mathrm{E}$, while the weakening cases occurred in the south flank of the SAH. Although the SAH was centered west of $90^{\circ} \mathrm{E}$, there was still an anticyclonic circulation on the northern side of Warren. In other words, the SAH maintained a center over China in the weakening cases.

The westward shift or breakdown of the SAH over China may result in the difference in TC-trough interaction between the RI and weakening cases, which can be indicated by the REFC at $200 \mathrm{hPa}$ (DeMaria et al. 1993). For the RI events, the REFC in the unfiltered data is $11.3,9.3$, and $1.4 \mathrm{~m} \mathrm{~s}^{-1}$ day $^{-1}$ at the RI onset for Kelly, Zeke, and Rammasun (Table 1), respectively.
For the weakening events, the REFC is $-0.1,-0.5$, and $-2.7 \mathrm{~m} \mathrm{~s}^{-1} \mathrm{day}^{-1}$ for Ellis, Warren, and Faye, respectively. As suggested by Chen et al. (2015), the relatively high REFC is a unique synoptic environmental feature for RI cases in the South China Sea. In agreement with Chen et al. (2015), the large-scale circulation pattern in the upper troposphere enhanced the TC-trough interaction in the three offshore RI events.

The WNPSH is an important component of the East Asia summer monsoon and generally determines the movement of the TCs from July to September over the WNP. Shu et al. (2014) investigated the influence of environmental conditions on the intensity changes of TCs over the western North Pacific by examining TCs that interacted with the subtropical high. By comparing the intensifying events and weakening events, they found that the environmental conditions associated with the subtropical high play important roles in the intensity changes of TCs. When TCs move along the 
$\mathrm{RI}$
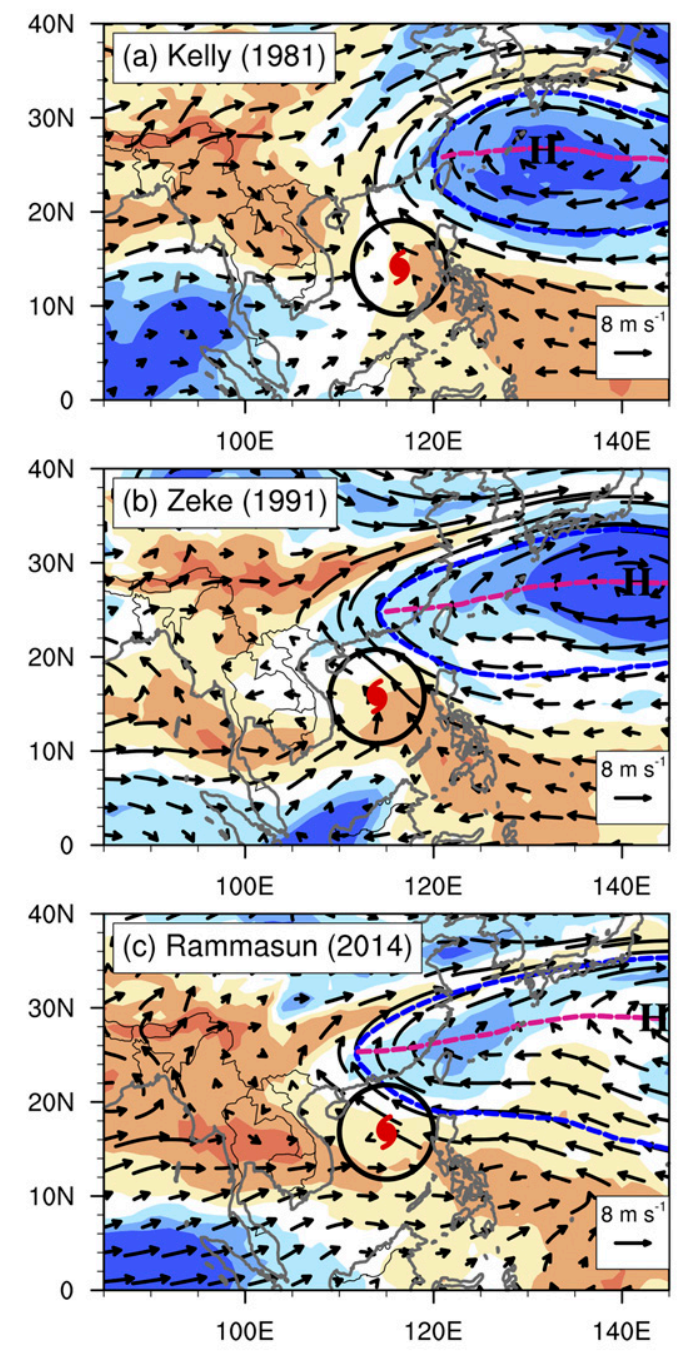

Weakening
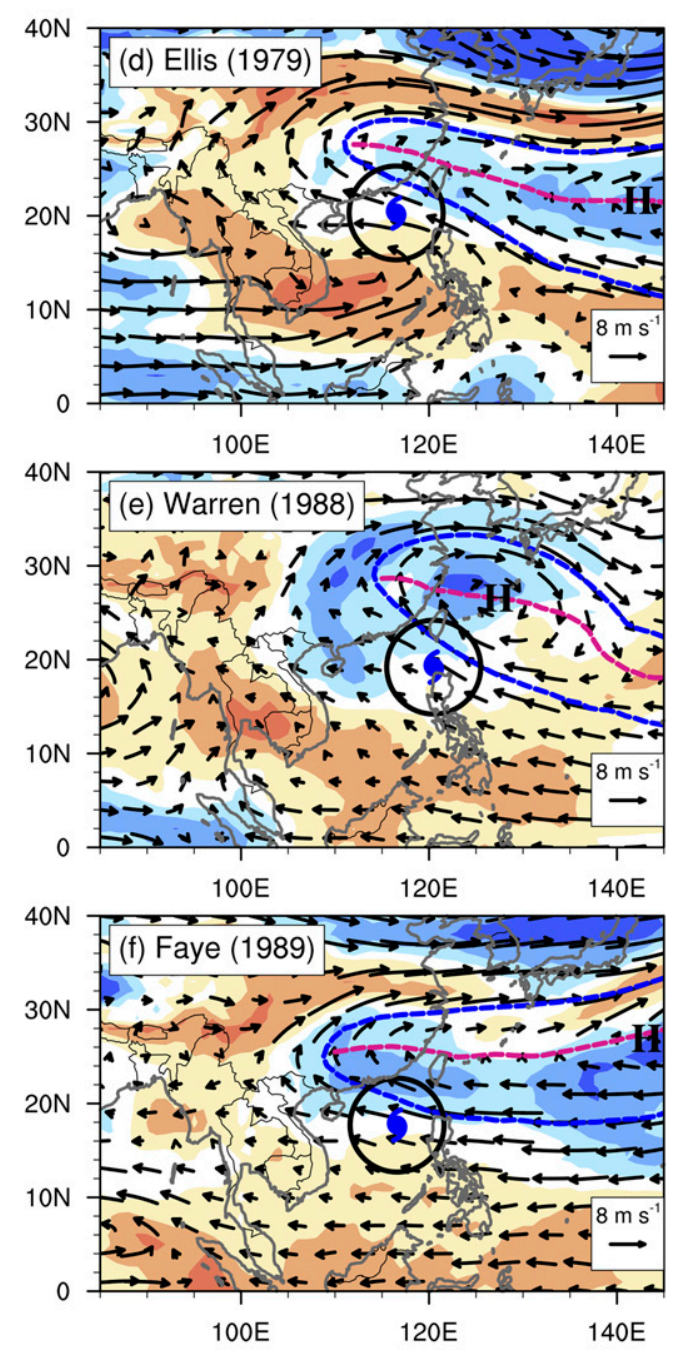

\begin{tabular}{|c|cc|c|c|c|}
\hline & & & & & \\
\hline 40 & 50 & 60 & 70 & 80 & 90 \\
& Relative humidity (\%)
\end{tabular}

FIG. 5. The 500-hPa filtered wind field (vectors), filtered relative humidity field (shaded), and the contour of 5880 gpm at $500 \mathrm{hPa}$ (thick blue line) at the onset for the RI cases of Typhoons Kelly (1981), Zeke (1991), and Rammasun (2014) and the weakening cases of Typhoons Ellis (1979), Warren (1988), and Faye (1989). The red (blue) typhoon symbol indicates the position of the TC center at the onset of the RI (weakening) cases. Black solid circles indicate the distance of $5^{\circ}$ from the TC center, and pink lines represent the ridge of the WNPSH.

western edge of the subtropical high, the strong westerly VWS promotes the intrusion of dry environmental air associated with the subtropical high, leading to the weakening of TCs. Figure 5 shows $500-\mathrm{hPa}$ wind field and $600-\mathrm{hPa}$ relative humidity derived from the lowpass-filtered data. For the RI cases, the ridge of the WNPSH was located north of $20^{\circ} \mathrm{N}$ at $120^{\circ} \mathrm{E}$. The relative humidity at $600 \mathrm{hPa}$ was generally higher than $60 \%$ within the radius of $500 \mathrm{~km}$ from the TC center. For the weakening cases, the ridge of the WNPSH was also located north of $20^{\circ} \mathrm{N}$ at $120^{\circ} \mathrm{E}$, but the TCs were located closer to the subtropical high. Relative humidity values lower than $60 \%$ can be clearly found within the radius of $500 \mathrm{~km}$ from the TC center. In Table 1, the average relative humidity within the radius of $500 \mathrm{~km}$ from the TC center is also shown. The average relative humidity in the weakening cases is lower than in the RI cases. Figure 5 suggests that the weakening cases were accompanied with the dry air intrusion associated with the subtropical high. 
$\mathrm{RI}$
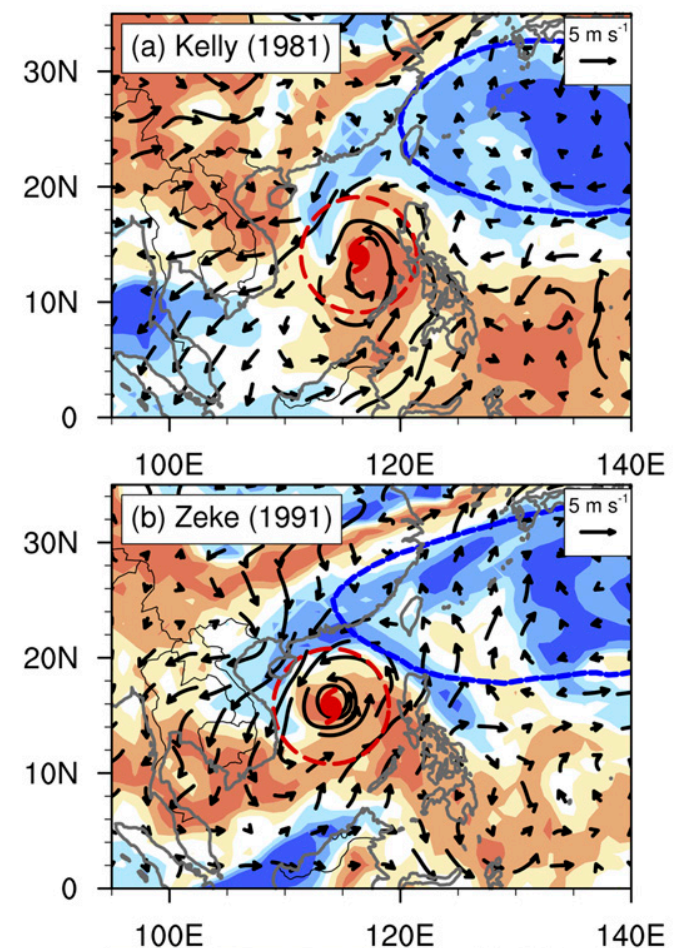

$100 \mathrm{E} \quad 120 \mathrm{E} \quad 140 \mathrm{E}$

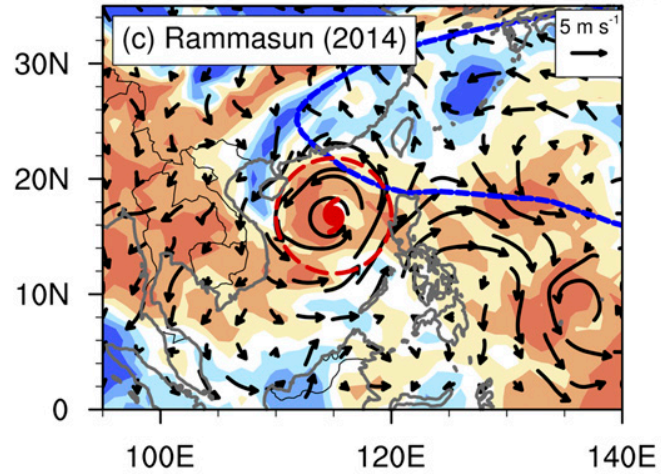

Weakening
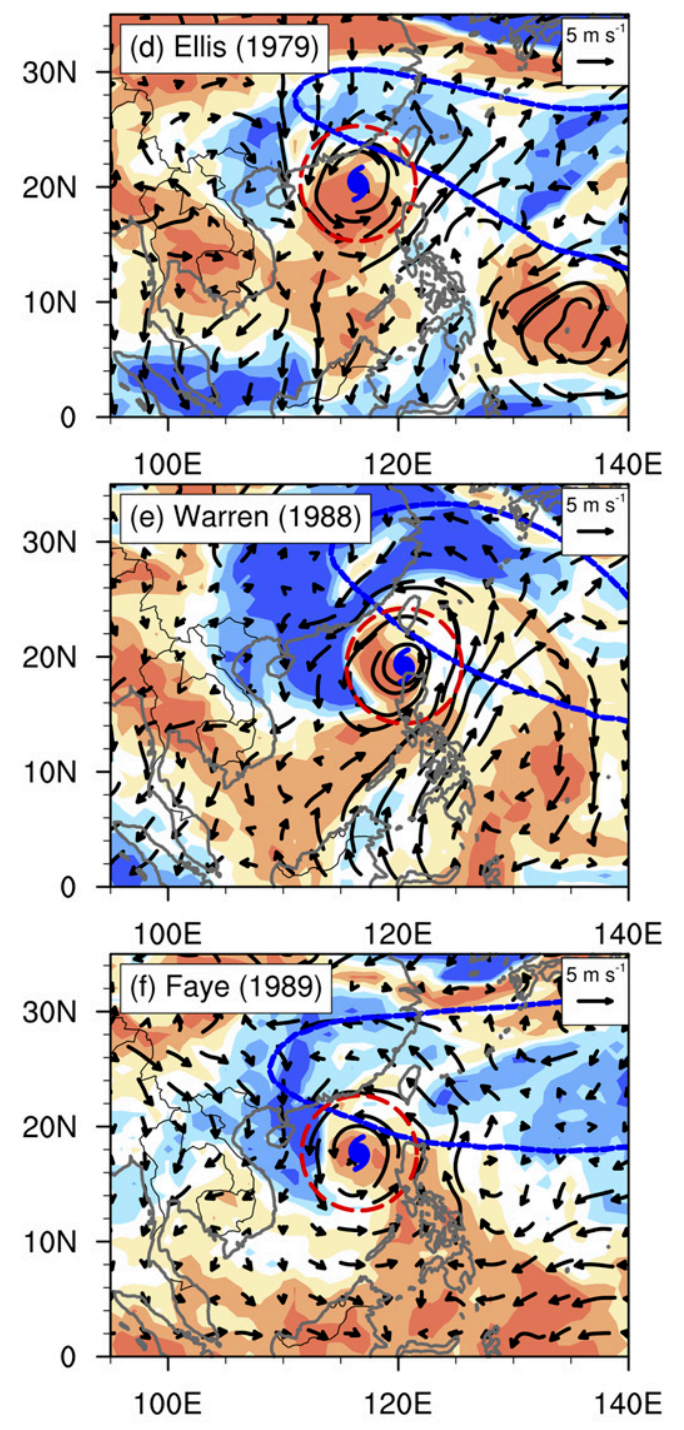

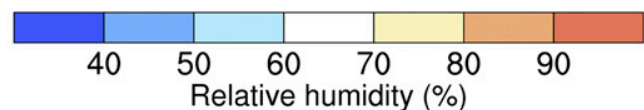

FIG. 6. As in Fig. 5, but for the 600-hPa synoptic-scale wind field (vectors) and unfiltered relative humidity field (shaded).

The dry intrusion that results from the interaction between the TC and WNPSH can be further demonstrated by the $600-\mathrm{hPa}$ unfiltered relative humidity and the synoptic-scale wind fields derived from the unfiltered and low-pass-filtered data (Fig. 6). This figure indicates that the relatively dry air of the WNPSH with relative humidity lower than $60 \%$ can penetrate the TC circulation on the north and northwest sides of the TC. However, the dry air intrusion is weaker in the RI cases than in the weakening cases, suggesting that the dry air intrusion is an important factor for the offshore RI.
The stronger dry air intrusion in the weakening cases may be due to the shorter distance between the TC and the WNPSH. As shown in Fig. 1b, the TCs in the weakening cases are located to the north of the TCs in the RI cases, closer to the WNPSH.

Forecasters in China have long recognized the importance of the moist air transport associated with the strengthening southwesterly monsoon flow on the southern flank of the monsoon trough, which is often called the monsoon surge. Figure 7 shows the $850-\mathrm{hPa}$ low-pass-filtered wind field and the water vapor flux. 
$\mathrm{RI}$
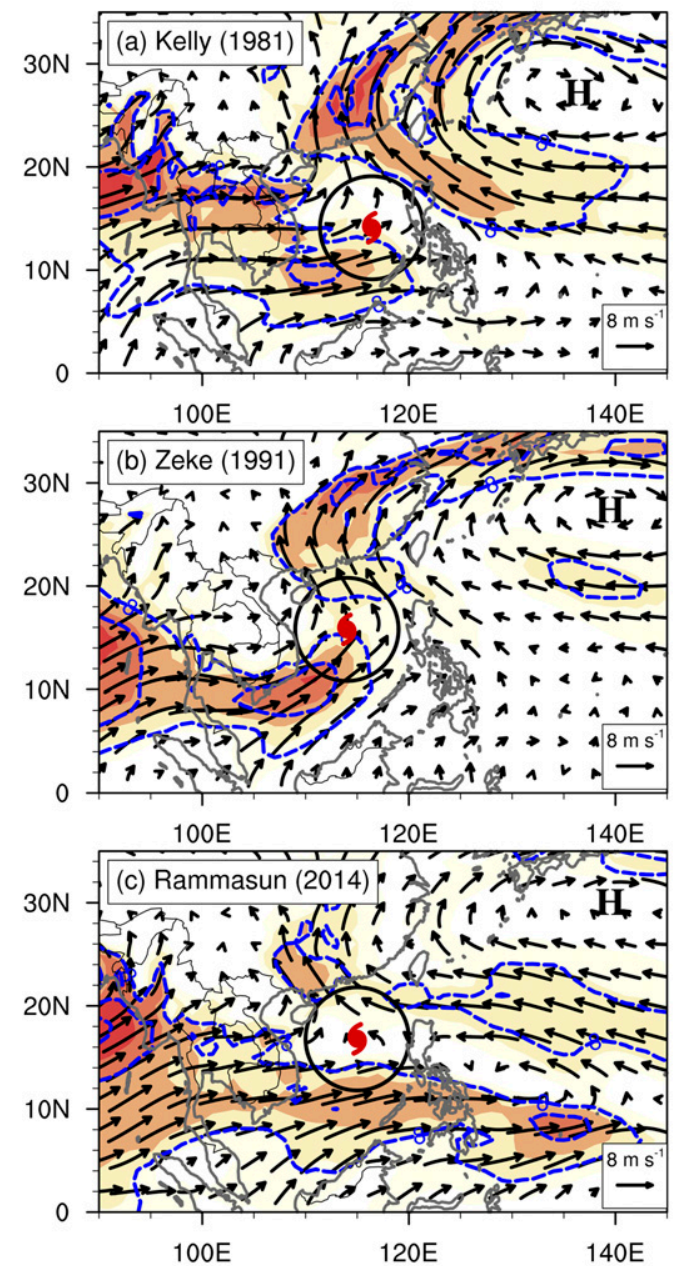

Weakening
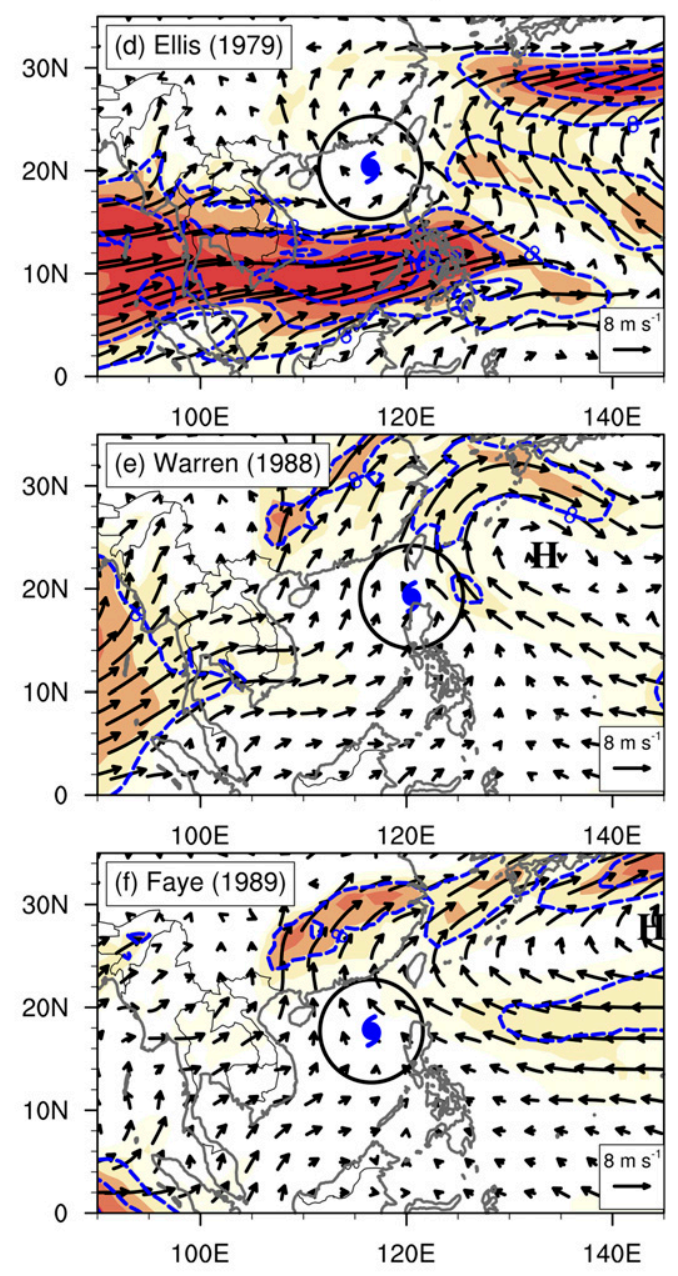

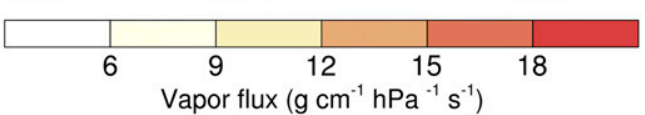

FIG. 7. The 850-hPa filtered wind field (vectors) and filtered water vapor flux (shaded) at the onset for the RI cases of Typhoons Kelly (1981), Zeke (1991), and Rammasun (2014) and the weakening cases of Typhoons Ellis (1979), Warren (1988), and Faye (1989). The red (blue) typhoon symbol indicates the position of the TC center at the onset of the RI (weakening) cases. Black solid circles indicate the distance of $5^{\circ}$ from the TC center, and blue lines are contours of the wind speed.

For the RI cases, the TCs were embedded in a welldeveloped monsoon trough and the water vapor was transported to the TC circulation along the southwesterly flow. The subtropical high extended to the continent and the water vapor was further transported to the inland of China. For the weakening case of Ellis, although the monsoon flow transported the water vapor to the monsoon trough, the enhanced transport was located to the south of the TC, suggesting that the enhanced water vapor did not penetrate the TC circulation. For the weakening cases of Warren and Faye, the monsoon trough did not well develop and the monsoon surge cannot be found.
This suggests that the water vapor transport associated with the monsoon flow into the TC circulation is important for the offshore RI of TCs in a sheared environment.

\section{Discussion}

The seasonal northward migration of the summer monsoon in East Asia includes three stationary stages and two abrupt northward shifts (Ding and Chan 2005). The stepwise movement of the East Asia monsoon is closely associated with the changes of large-scale circulations such as the SAH, WNPSH, and MT, as well as the 
primary rainbelt in China. The three stationary stages correspond to the presummer rainy season in South China, the mei-yu season in the Yangtze River valley, and the rainy season in North China. The two sudden northward jumps signify the onset of the mei-yu season in the Yangtze River valley and the rainy season in North China. The RI events of Kelly (1981), Zeke (1991), and Rammasun (2014) started on 2 July 1981, 12 July 1991, and 17 July 2014, respectively. By comparing the ending date of the mei-yu season in Jiangsu Province, we find that the RI in the sheared environment occurred 1-3 days prior to the termination of the mei-yu season. The timing of the RI in the sheared environment coincides with that of the adjustment of the large-scale atmospheric circulations.

In general, the ridge of the WNPSH shifts north of $27^{\circ} \mathrm{N}$ by the end of the mei-yu season and the primary rainbelt moves to North China. Wei et al. (2015) investigated the influence of the condensational heating associated with the mei-yu precipitation on the SAH and found that the condensational heating excites a local anticyclone in the upper troposphere and leads to the eastward extension of the SAH. As shown in Fig. 4, it is suggested that the weakening or westward withdrawal of the SAH in the RI cases may be associated with the termination of the mei-yu season. Meanwhile, as an important member of the Asian monsoon system (Krishnamurti and Bhalme 1976; Tao and Chen 1987), the westward withdrawal of the SAH corresponds to the enhancement of the monsoon flow, which is also shown in Wei et al. (2014). As discussed above, the configuration of the large-scale circulation in the upper troposphere can also enhance the TC-trough interaction in the three offshore RI events.

In association with the adjustment of the large-scale circulations, the water vapor transport associated with the monsoon flow can reach North China through the monsoon trough in the South China Sea. It is important for the enhanced transport of water vapor to penetrate the TC circulation. Recent studies suggested that convective bursts inside the radius of maximum wind play an important role in the RI with moderate VWS (Reasor et al. 2009; Rogers et al. 2016; Zawislak et al. 2016; Leighton et al. 2018). Chen and Gopalakrishnan (2015) investigated the asymmetric RI of Hurricane Earl (2010) and argued that persistent convective bursts in the downshear-left quadrant are favorable for the RI in a sheared environment. The downdrafts of the convective bursts enhance the upper-level warming in the eye, leading to the RI of Hurricane Earl (2010). In the three RI cases discussed in this study, the VWS between 200 and $850 \mathrm{hPa}$ was generally easterly and thus the convective bursts are generally triggered on the southwestern side of the TC (downshear-left). The penetration of water vapor associated with the monsoon surge is favorable for the convective bursts within the radius of maximum wind and thus TCs can experience the RI in a sheared environment. Further study is needed to demonstrate the penetration of the monsoon surge into the TC circulation and the associated effect.

\section{Conclusions}

The offshore RI in a sheared environment is examined for the TCs that made landfall in China during 19792017. It is found that the offshore RI in a sheared environment is a relatively rare event. The detected three offshore RI events in a sheared environment occurred in early to mid-July, 1-3 days prior to the termination of the mei-yu season in the Yangtze River valley. The offshore RI events all took place to the south of Hainan Island within the monsoon trough. Our study suggests that the forecaster should consider the possibility of an offshore RI event when a TC is over the South China Sea just prior to the termination of the mei-yu season in the Yangtze River valley.

This study reveals two possible environmental factors that are responsible for the offshore RI in a sheared environment. One is intrusion of the dry air associated with the WNPSH and the other is the penetration of the water vapor flux associated with the monsoon surge. We argue that the specific geographic location and timing of the occurrence of the offshore RI in the sheared environment is mainly due to the adjustment of the largescale circulation when the mei-yu season terminates in the Yangtze River valley. The termination of the mei-yu season is closely associated with the adjustment of largescale circulations such as the SAH, WNPSH and monsoon trough. The adjustment makes the water vapor flux of the monsoon surge penetrate the inner region of the TC and prevents the dry air associated with the WNPSH from intruding into the TC circulation. In addition, the calculation of the REFC also suggests that the adjustment enhances the TC-trough interaction in the upper troposphere, favorable for TC intensification.

As mentioned in the introduction, observational and numerical studies have confirmed the occurrence of RI in an environment with VWS larger than $10 \mathrm{~m} \mathrm{~s}^{-1}$ (Molinari et al. 2006; Molinari and Vollaro 2010; Chen et al. 2015). As a specific type of RI, this study shows that the offshore RI in a sheared environment can occur 1-3 days prior to the termination of the mei-yu season in the Yangtze River valley, although it is based only on three offshore RI cases. To confirm the robustness of our conclusions, future studies can be conducted in the following two aspects. One is to perform the 
numerical simulation of the real offshore RI cases discussed in this study. Since high-resolution climate models can simulate relatively realistic intensification of TCs (Roberts et al. 2015; Vecchi et al. 2019), the other is to examine TCs from high-resolution simulations with climate models, which may substantially increase the sample size.

Acknowledgments. We greatly appreciate the constructive comments from three anonymous reviewers. This research was jointly supported by the National Basic Research Program of China (2015CB452803), the National Natural Science Foundation of China (NSFC 41730961, 41675051, 41675009, and 41675042), and the Open Research Program of the State Key Laboratory of Severe Weather (2019LASW-A02). This work is also supported by the China Scholarship Council.

\section{REFERENCES}

Chen, H., and S. G. Gopalakrishnan, 2015: A study on the asymmetric rapid intensification of Hurricane Earl (2010) using the HWRF system. J. Atmos. Sci., 72, 531-550, https://doi.org/ 10.1175/JAS-D-14-0097.1.

Chen, X., Y. Wang, and K. Zhao, 2015: Synoptic flow patterns and large-scale characteristics associated with rapidly intensifying tropical cyclones in the South China Sea. Mon. Wea. Rev., 143, 64-87, https://doi.org/10.1175/MWR-D-13-00338.1.

,-- J. Fang, and M. Xue, 2018: A numerical study on rapid intensification of typhoon Vicente (2012) in the South China Sea. Part II: Roles of inner-core processes. J. Atmos. Sci., $\mathbf{7 5}$, 235-255, https://doi.org/10.1175/JAS-D-17-0129.1.

DeMaria, M., J.-J. Baik, and J. Kaplan, 1993: Upper-level eddy angular momentum fluxes and tropical cyclone intensity change. J. Atmos. Sci., 50, 1133-1147, https://doi.org/10.1175/ 1520-0469(1993)050<1133:ULEAMF > 2.0.CO;2.

Ding, Y., and J. C. L. Chan, 2005: The East Asian summer monsoon: An overview. Meteor. Atmos. Phys., 89, 117-142, https:// doi.org/10.1007/s00703-005-0125-z.

Hanley, D., J. Molinari, and D. Keyser, 2001: A composite study of the interactions between tropical cyclones and upper-tropospheric troughs. Mon. Wea. Rev., 129, 2570-2584, https://doi.org/10.1175/ 1520-0493(2001)129<2570:ACSOTI>2.0.CO;2.

Holliday, C. R., and A. H. Thompson, 1979: Climatological characteristics of rapidly intensifying typhoons. Mon. Wea. Rev., 107, 1022-1034, https://doi.org/10.1175/1520-0493(1979)107<1022: CCORIT $>2.0 . \mathrm{CO} ; 2$.

Hsu, H.-H., C.-H. Hung, A.-K. Lo, C.-C. Wu, and C.-W. Hung, 2008: Influence of tropical cyclones on the estimation of climate variability in the tropical western North Pacific. J. Climate, 21, 2960-2975, https://doi.org/10.1175/2007JCLI1847.1.

Huang, B., and Coauthors, 2015: Extended Reconstructed Sea Surface Temperature version 4 (ERSST.v4). Part I: Upgrades and intercomparisons. J. Climate, 28, 911-930, https://doi.org/ 10.1175/JCLI-D-14-00006.1.

Kaplan, J., and M. DeMaria, 2003: Large-scale characteristics of rapidly intensifying tropical cyclones in the North Atlantic basin. Wea. Forecasting, 18, 1093-1108, https://doi.org/ 10.1175/1520-0434(2003)018<1093:LCORIT > 2.0.CO;2.
,-- , and J. A. Knaff, 2010: A revised tropical cyclone rapid intensification index for the Atlantic and eastern North Pacific basins. Wea. Forecasting, 25, 220-241, https://doi.org/10.1175/ 2009WAF2222280.1.

Krishnamurti, T. N., and H. N. Bhalme, 1976: Oscillations of a monsoon system. Part I: Observational aspects. J. Atmos. Sci., 33, 1937-1954, https://doi.org/10.1175/1520-0469(1976) 033<1937:OOAMSP $>2.0 . \mathrm{CO} ; 2$.

Kurihara, Y., M. A. Bender, and R. J. Ross, 1993: An initialization scheme of hurricane models by vortex specification. Mon. Wea. Rev., 121, 2030-2045, https://doi.org/10.1175/ 1520-0493(1993)121<2030:AISOHM>2.0.CO;2.

,,- R. E. Tuleya, and R. J. Ross, 1995: Improvements in the GFDL hurricane prediction system. Mon. Wea. Rev., 123, 2791-2801, https://doi.org/10.1175/1520-0493(1995)123<2791: IITGHP $>2.0 . \mathrm{CO} ; 2$.

Leighton, S. P., L. Nerurkar, R. Krishnadas, C. Johnman, G. J. Graham, and J. Cavanagh, 2018: Chemokines in depression in health and in inflammatory illness: A systematic review and meta-analysis. Mol. Psychiatry, 23, 48-58, https://doi.org/ 10.1038/mp.2017.205.

Liu, C., and G. Rong, 1995: The climatic analysis of the relationship between the explosive development of typhoon and its environment flow field (in Chinese). J. Trop. Meteor., 11, 52-56.

Molinari, J., and D. Vollaro, 2010: Rapid intensification of a sheared tropical storm. Mon. Wea. Rev., 138, 3869-3885, https://doi.org/10.1175/2010MWR3378.1.

—, S. Skubis, and D. Vollaro, 1995: External influences on hurricane intensity. Part III: Potential vorticity structure. J. Atmos. Sci., 52, 3593-3606, https://doi.org/10.1175/15200469(1995)052<3593:EIOHIP > 2.0.CO;2.

— P. Dodge, D. Vollaro, K. L. Corbosiero, and F. Marks, 2006: Mesoscale aspects of the downshear reformation of a tropical cyclone. J. Atmos. Sci., 63, 341-354, https://doi.org/10.1175/ JAS3591.1.

Qin, N., D.-L. Zhang, and Y. Li, 2016: A statistical analysis of steady eyewall sizes associated with rapidly intensifying hurricanes. Wea. Forecasting, 31, 737-742, https://doi.org/10.1175/ WAF-D-16-0016.1.

Reasor, P. D., M. D. Eastin, and J. F. Gamache, 2009: Rapidly intensifying Hurricane Guillermo (1997). Part I: Lowwavenumber structure and evolution. Mon. Wea. Rev., 137, 603-631, https://doi.org/10.1175/2008MWR2487.1.

Roberts, M. J., and Coauthors, 2015: Tropical cyclones in the UPSCALE ensemble of high-resolution global climate models. J. Climate, 28, 574-596, https://doi.org/10.1175/ JCLI-D-14-00131.1.

Rogers, R. F., J. A. Zhang, J. Zawislak, H. Jiang, G. R. Alvey, E. J. Zipser, and S. N. Stevenson, 2016: Observations of the structure and evolution of Hurricane Edouard (2014) during intensity change. Part II: Kinematic structure and the distribution of deep convection. Mon. Wea. Rev., 144, 3355-3376, https://doi.org/ 10.1175/MWR-D-16-0017.1.

Shieh, O. H., M. Fiorino, M. E. Kucas, and B. Wang, 2013: Extreme rapid intensification of Typhoon Vicente (2012) in the South China Sea. Wea. Forecasting, 28, 1578-1587, https://doi.org/ 10.1175/WAF-D-13-00076.1.

Shu, S., J. Ming, and P. Chi, 2012: Large-scale characteristics and probability of rapidly intensifying tropical cyclones in the western North Pacific basin. Wea. Forecasting, 27, 411-423, https://doi.org/10.1175/WAF-D-11-00042.1.

, F. Zhang, J. Ming, and Y. Wang, 2014: Environmental influences on the intensity changes of tropical cyclones over the 
western North Pacific. Atmos. Chem. Phys., 14, 6329-6342, https://doi.org/10.5194/acp-14-6329-2014.

Tao, S. Y., and L. X. Chen, 1987: A review of recent research on the East Asian summer monsoon in China. Monsoon Meteorology, C.-P. Chang and T. N. Krishnamurti, Eds., Oxford University Press, 60-92.

Titley, D. W., and R. L. Elsberry, 2000: Large intensity changes in tropical cyclones: A case study of supertyphoon Flo during TCM-90. Mon. Wea. Rev., 128, 3556-3573, https://doi.org/ 10.1175/1520-0493(2000)128<3556:LICITC >2.0.CO;2.

Vecchi, G. A., and Coauthors, 2019: Tropical cyclone sensitivities to $\mathrm{CO}_{2}$ doubling: Roles of atmospheric resolution, synoptic variability and background climate changes. Climate Dyn., 53, 5999-6033, https://doi.org/10.1007/s00382-019-04913-y.

Wang, B., and X. Zhou, 2008: Climate variation and prediction of rapid intensification in tropical cyclones in the western North Pacific. Meteor. Atmos. Phys., 99, 1-16, https://doi.org/10.1007/ s00703-006-0238-z.

Wang, Y., Y. Rao, Z.-M. Tan, and D. Schönemann, 2015: A statistical analysis of the effects of vertical wind shear on tropical cyclone intensity change over the western North Pacific. Mon. Wea. Rev., 143, 3434-3453, https://doi.org/10.1175/MWR-D-15-0049.1.

Wei, W., R. Zhang, M. Wen, X. Rong, and T. Li, 2014: Impact of Indian summer monsoon on the South Asian high and its influence on summer rainfall over China. Climate Dyn., $\mathbf{4 3}$ 1257-1269, https://doi.org/10.1007/s00382-013-1938-y.

— B.-J. Kim, and J.-C. Nam, 2015: Interannual variation of the South Asian high and its relation with Indian and East Asian summer monsoon rainfall. J. Climate, 28, 2623-2634, https://doi.org/10.1175/JCLI-D-14-00454.1.

Wu, L., and H. Zhao, 2012: Dynamically derived tropical cyclone intensity changes over the western North Pacific. J. Climate, 25, 89-98, https://doi.org/10.1175/2011JCLI4139.1.

Ying, M., W. Zhang, H. Yu, X. Lu, J. Feng, Y. Fan, Y. Zhu, and D. Chen, 2014: An overview of the China Meteorological Administration tropical cyclone database. J. Atmos. Oceanic Technol., 31, 287-301, https://doi.org/10.1175/JTECH-D-1200119.1.

Zawislak, J., H. Jiang, G. R. Alvey, E. J. Zipser, R. F. Rogers, J. A Zhang, and S. N. Stevenson, 2016: Observations of the structure and evolution of Hurricane Edouard (2014) during intensity change. Part I: Relationship between the thermodynamic structure and precipitation. Mon. Wea. Rev., 144, 3333-3354, https://doi.org/10.1175/MWR-D-16-0018.1.

Zong, H., and L. Wu, 2015: Re-examination of tropical cyclone formation in monsoon troughs over the western North Pacific. Adv. Atmos. Sci., 32, 924-934, https://doi.org/10.1007/s00376014-4115-2. 